\title{
Haemovigilance Fact and Fiction
}

\section{Smit Sibinga CTh ${ }^{1 *}$ and Abdella $\mathrm{YE}^{2}$}

${ }^{1}$ Consultant, IQM Consulting and University of Groningen, Netherlands

${ }^{2}$ Medical Officer, World Health Organization Regional Office for the Eastern Mediterranean, Egypt

*Corresponding author: Cees Smit Sibinga, Consultant IQM Consulting and University of Groningen, Netherlands, Tel: 31-594-502670; Email: c.sibinga@planet.nl

\section{Editorial}

Volume 4 Issue 1

Received Date: May 25, 2020

Published Date: June 01, 2020

DOI: $10.23880 /$ hij-16000163

\section{Introduction}

Vigilance comes from the Latin vigilare which means 'keeping awake', or 'being alert'. In practice it translates into a surveillancemechanism to watch characteristics of something, e.g., pharmaceuticals (pharmacovigilance), biologicals (biovigilance) and blood products (haemovigilance). The observations start at the consumer side, tracing back to the origin, root cause.

The question then arises - 'What is being watched?'

In principle the watching process relates to the final outcome of a manufacturing process and the application of the outcome. Pharmacovigilance watches or observes the clinical efficacy of pharmaceuticals, expected and adverse. Haemovigilance is a surveillance system watching the clinical efficacy of blood products, expected and adverse. The purpose is improvement through the detection and analysis of aberrations and deviations from set standards in the vein-to-vein lifeline of blood and blood components. That implicates the existence of a meticulous and well-organized system of tracing back each and every step of the lifeline through documentation. The standards include the technical and quality requirements and serve as the key reference against which the expected and adverse outcomes are benchmarked. To bring that into practice well-educated and competent personnel are needed. Competency represents adequate knowledge and skills to understand the values of the outcomes and be able to address the consequences of the observations as an act of professional performance.

Performance of the blood supply and consumption or clinical use in general follows the 5 key elements of Quality System Management [1]

a) Organization, (infra-)Structure and Leadership;

b) Standards/ References and Guidelines

c) Documentation (quality pyramid with its 4 levels);

d) Education (teaching and training, maintaining competency);

e) Assessment - monitoring and evaluation (M\&E).

Haemovigilance, as a quality gatekeeping surveillance tool, is an integral part of the assessment element, based on continuous M\&E of what has been done, and whether that matches standards of performance, quality and technical. To trace development statistical process control (SPC) [2], Six Sigma [3] and Safety-I and Safety-II [4] are used, where the tracking is based on waterproof documentation. Hence, as a matter of fact haemovigilance is an integral part of the blood transfusion chain, a gate keeping tool to sustain overall quality [5].

Haemovigilance came to life in France following the haemophilia HIV drama in the 1980s and is now being advocated worldwide [6,7]. Recognizing its importance, WHO issued an Aide Mémoire on national haemovigilance systems in 2015, a guide in establishing national haemovigilance system in 2016 and advocated for it in its 2020 Action framework, as part of a quality culture and management in the blood system [7-9]. However, there is distinct difference between advocating the principles as part of a quality culture and management (first the pudding, then the tasting), and stimulating the set-up and implementation as a seemingly stand-alone operation without observing the totality. In other words, using the vigilance as a 'pars pro toto'; a clear fiction!

To analyse this phenomenon haemovigilance systems and management were evaluated for 35 countries (2001-2019) in 5 WHO Regions as part of development projects focused on strengthening existing blood transfusion structures (vein-to-vein). These projects were based on a step-by-step introduction of the concept and principles of quality and its management and operational culture. Beneficiaries were solicited to indicate their priority interventions in achieving satisfactory progress in their quality and operational 


\section{Haematology International Journal}

development $[10,11]$.

To cover global representation, five WHO Regions and 35 countries were involved:

Europe (Newly Independent States/Central Asia)-7;

Africa (Sub-Sahara)-4;

Eastern Mediterranean-19;

South-East Asia-3;

Western Pacific-2

These 35 Countries belong to low and medium UNDP Human Development Index (L- and M-HDI) groups. Their blood supply and transfusion operations range from a highly fragmented public and private structure to a regionalized national blood transfusion organization. At the beginning of the respective strengthening through development projects none of them had a quality system and management in place, no current national standards and a grossly underdeveloped non-structured documentation practice. Staff competence showed major knowledge gaps at all levels, particularly among blood prescribing clinicians. Haemovigilance in the true sense of the word was virtually non-developed, albeit listed a high priority intervention.

A majority of countries (62.8\%) listed haemovigilance a top priority - $22 / 35$, or a 2 nd or 3rd priority (37.2\%) $12 / 35$. Only 3 more advanced countries (8.6\%) understood the importance to first have the managerial and operational vein-to-vein framework developed and implemented (the pudding) before assuring the managerial and operational quality and efficacy of the final procurement and operational outcomes (the tasting).

The lesson learned is: haemovigilance was and in many situations still is virtually non-developed, albeit listed a high priority in the majority of L- and M-HDI countries: a fact and fiction problem. WHO in its 2020 Action framework [10] recommends the identification of the following high-level outcomes:

1) There is a national system for standardized data collection and reporting, and mechanisms to ensure uniform implementation.

2) There are systems for traceability, surveillance, haemovigilance and pharmacovigilance at national and organizational levels.
Fundamental to haemovigilance, as a quality gatekeeping surveillance and overall assessment tool, is a well-developed quality-based vein-to-vein blood transfusion organization and related quality culture and quality system management with proper understanding of assessment through M\&E values.

\section{References}

1. Smit Sibinga CTh, Seidl C, Nunes E, Aubuchon JP (2013) Quality and Quality Management Systems Applicable in Transfusion Medicine. In: Smit Sibinga CTh (Eds.), Quality Management in Transfusion Medicine. Nova Scientific Publishers, Inc. New York, NY, USA, pp: 55-130.

2. Statistical Process Control (1999) Oakland JS, Butterworth \& Heinemann, Oxford, UK.

3. Simple Six Sigma for Blood Banking, Transfusion and Cellular Therapy (2007) Walters LM, and Carpenter Badley JK (Eds.), AABB Press Bethesda, MD, USA.

4. Safety-I and Safety-II (2014) The Past and Future of Safety Management. In: Hollnagel E (Eds.), CRC Press, Boca Raton, London, New York.

5. Hemovigilance: An effective tool for improving transfusion safety (2012) In: De Vries RP, Faber JC, (Eds.), Wiley-Blackwell Publishers, Oxford, UK.

6. Williamson LM, Strong D (2013) Haemovigilance: Big brother or Kindly Light?. In: Smit Sibinga CTh (Eds.), Quality Management in Transfusion Medicine. Nova Scientific Publishers, Inc. New York, NY, USA pp: 209221.

7. WHO (2020) Action framework to advance universal access to safe, effective and quality-assured blood products 2020-2023. Geneva, World Health Organization. pp: 20-21.

8. Aide-memoir. National Haemovigilance System.

9. A guide in establishing national haemovigilance system.

10. WHO (2017) Strategic framework for blood safety and availability 2016-2025. Cairo, WHO Regional Office for the Eastern Mediterranean. 